\title{
EFFECTS OF VIDEO DISPLAY TERMINAL RESOLUTIONS TO THE LEGIBILITY OF TEXT ON A WEB PAGE
}

\author{
Ahmad Affendi Hashim ${ }^{1}$ and Mazlina Abdul Majid ${ }^{1}$ \\ ${ }^{1,2}$ Faculty of Computer Systems \& Software Engineering, Universiti Malaysia Pahang, \\ 26300 Gambang, Pahang, Malaysia \\ Email: affendi.hashim@gmail.com
}

\begin{abstract}
Higher Video Display Terminal (VDT) resolutions have been proven to provide better quality in improving image quality displayed. The higher the resolution means more pixels per-inch-square available to display an image. This increase, however, may not be to the fonts used on web pages for improved legibility. Legibility of web text has been proved essential to ensure the quality of a web page. Support by the evidence from the previous research experiment results; low level of web text legibility can cause various visual related problems and usability of a web page. This research will focus on finding possible improvement effects on VDT resolution that might need to be considered in designing the web text. In this research 6 font types and two VDT resolutions for low and high have been selected. Approximately 200 subjects were randomly selected for this experiment. The selected subjects were divided into two groups for low and high resolution. Selected subjects performed legibility test and subjective preference test experiments on 6 selected type of fonts. Overall findings indicate that there is an improvement but no significant difference between the two VDT resolutions.
\end{abstract}

Keywords:Legibility; Web text; Video Display Terminal; Fonts; Resolutions.

\section{INTRODUCTION}

One of the segments usually found on a webpage is the main content. The main content usually contains a series of text that will be the main focus of the user visits the web page. Backed by previous researches that are done by (Duckett, 2002) on readers reading strategy and (Nielsen and Pernice, 2010) on their eye tracking studies. Users actually scan web pages for relevant content related to the information they are looking for and not the whole content. On separate studies did by (Nielsen, 2008), on average, users actually only read about $20 \%$ of the whole text.Based on this evidence of how user's reading behaviour and how little actually user read the web text, the quality of a web text is crucial and needs to be taken care seriously. There are two main factors influencing the quality of web text; the quality of information presented (the content), and the quality of presentations. On the quality of presentation, one of the main factors is the legibility of the web text. Legibility is defined as "the quality of being clear enough to read" from the Oxford Dictionaries.On web text design, besides the colour combination used on the web text and the background, based on previous research, certain type and size of fonts does have a significant advantage in terms of legibility performance.This research however will explore even further, by studying the effects or the improvement on web text legibility that might improve when using much higher VDT resolution setting. The higher the VDT resolution the more density the pixel is. These higher pixel densities have proved to increase the quality of an image displayed but unproven that it might also increase the legibility of web text. Due to this unanswered question, this research will first explored the researches done previously on web text 
legibility, followed by presenting the design of the experiment used in this research and finally followed by presenting the results, discussion and conclusion of this research.

\section{WEB TEXT LEGIBILITY}

On this segment, the researches done previously on web text legibility, focussing on fonts characteristics will be explored. Based on the previous researches, there are four font characteristics that have been the main focus on text legibility studies. First is the type of fonts, serif and sans serif. Second is the category of fonts, fonts design for on-screen viewing and fonts designed for printed materials. Third is the design of the fonts itself, that are focussed on descenders, ascender, counter, baseline and x-height. Finally, the font size that has proven to influence the legibility will be presented in this section.

\section{FONTS ON LEGIBILITY}

Recent research suggests that choosing the right font size and type of fonts can affect the legibility of a webpage. On font size, the conclusion is simple, the larger the font size used, the better the legibility is. However, too large font size might introduce readability problem, such as, a necessary to scroll the web page just to read the whole text. On type of fonts, the legibility is influenced by the characteristics or design of the fonts. Characteristics of the fonts are, serif and sans serif, and the category of fonts, which are fonts design for printed materials and fonts design for on-screen viewing.

\section{A. SERIF VERSUS SAN SERIF}

Serif and sans serif are the two main categories of fonts design. Serif fonts have curls or an extra stroke at the end of each letter. Typefaces or fonts that do not have serifs are called sans serif. Figure 1 illustrates the difference between serif and sans serif fonts.

\section{Serif \\ Sans Serif}

Serif font

Sans serif font

Figure 1. Serif and Sans Serif font

There are a few researcher focusing in this area. The most recent research is done by (Soleimani and Mohammadi, 2012). They investigate the effects of font selection on comprehension and information recalling. Their research result however did not indicate any significant advantage between the serif and sans serif fonts. (Banerjee, Majumdar, and Pal, 2011) however, have found serif fonts are more legible than sans serif fonts. Banerjee et al. have proved that, based on individual reading performance, selected on their study indicates that, serif fonts performance is significantly better compared to sans serif fonts. (Moret-Tatay and Perea, 2011) in their study on, lexical decision experiment on serif and sans serif fonts, have concluded a different results. They have suggested that, sans serif fonts are the best font to be used for on screen text. There are some more researchers who have concluded different results based on their studies. (Erdogan, 2008) found Verdana (sans serif) font is better compared to Times New Roman (serif) and Courier New (monotype) font. While (Arditi and Cho, 2005) have discovered that, visual acuity for the serif fonts is better than sans serif fonts due to extra space required for the serif. Based on the results of the previous researcher, the results are still inconclusive whether serif or sans serif 
fonts actually have a significant legibility advantage or not. Previous researches also does not indicate any evidence that VDT resolutions could improve or shows any significant advantage between serif and sans serif fonts.

\section{B. ON-SCREEN FONTS VERSUS PRINTED FONTS}

Most of the fonts are actually designed and optimized to be viewing either on screen or in printed materials. Fonts design for on screen viewing, is enhanced to increase the readability level when viewing on screen. A clear enhancement made to the fonts designed for on screen viewing is the x-height of the font. According to (Boyarski,Neuwirth, Forlizzi, and Regli, 1998) and (Poulton, 1965), x-height of a font is proved to have influenced the legibility level. The larger x-height means, the taller the font is. Fig. 2 shows the difference between Verdana (font designed for on screen viewing) and Times New Roman (font designed for printed materials) with both on 10 point (pt) in size.

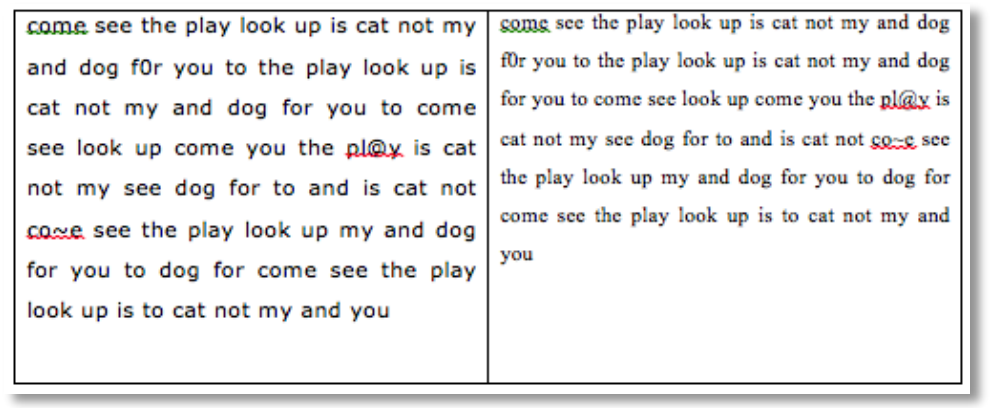

Figure 2. Verdana (Left) and Times New Roman (Right) on $10 \mathrm{pt}$

Recent researches on the type of fonts have also proved that, $\mathrm{x}$-height that is different for each type of fonts, is found to be significantly influencing the legibility. (Camnalbur and Mutlu, 2011) who did review on typography have found out that the Arial font which has higher $\mathrm{x}$-height compared to Times New Roman does have an advantage in terms of size.

(Beymer, Russell, and Orton, 2008) in their study using eye-tracking technique, has proved the Georgia font which was designed for clarity for on-screen viewing is $7.9 \%$ faster on reading time compared to Helvetica which was designed for signage. (B. S. Chaparro, Shaikh, and Chaparro, 2006) did studies on the legibility of 6 selected fonts.Based on their experiment on character identification, indicate that, Verdana does have advantages compared to Times New Roman. Explicitly mention, the Times New Roman font is found to be more confused with both letters and other symbols based on the result of their character identification experiment. (Sheedy, Subbaram, Zimmerman, and Hayes, 2005) experiment result also agrees with the findings on more recent researchers. On their studies on 4 types of fonts have found out that, fonts designed for on-screen viewing is more legible compared to fonts specifically designed for printed. (Weisenmiller, 1999), on p. 81 research results however, does indicate the advantages of on-screen fonts but not significant.

\section{COMPARISON BETWEEN TYPE OF FONTS}

Besides the aesthetic designs or the shape of characters that influence the legibility of the fonts, $\mathrm{x}$-height, ascender, descender and character spacing also influence the legibility level of a font. $\mathrm{X}$-height is basically is a height of character " $\mathrm{x}$ " in a font that determined the height or how tall the characters in a font.The higher the x-height makes the characters become larger and thus more legible. Besides the $\mathrm{x}$-height, ascender and descender also influenced the legibility level of 
a font. (V. M. Subbaram, 2004), on p. 198 has proved that ascender and descender do improve legibility.Meanwhile, on the characters spacing, the larger the space between the characters the more distinctive the characters are.Recent study conducted by (Ou, Sun, Huang, and Ronnier Luo (2014), and Hojjati and Muniandy (2014) also agree with character spacing influence the level of legibility. Fig. 3 illustrates the $x$-height, ascenders and descenders that are found in the font.

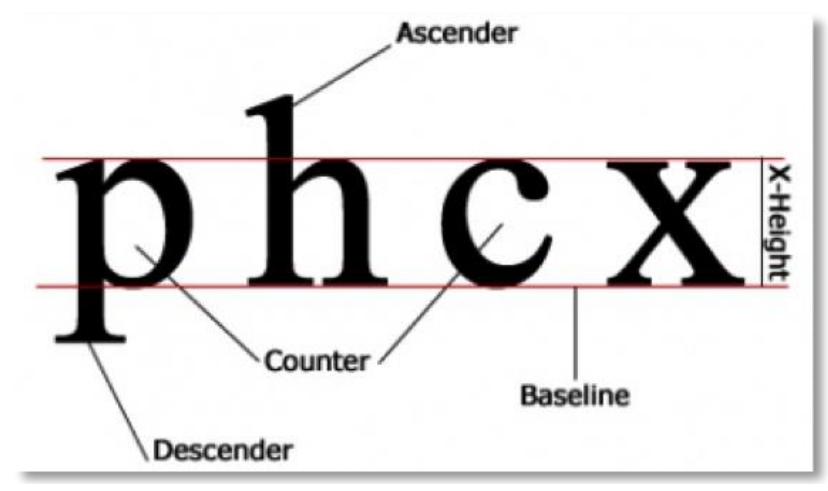

Figure 3. Illustrations on $\mathrm{x}$-height, descenders and ascenders

As a conclusion, the $\mathrm{x}$-height, descenders, ascenders and characters spacing does determine the legibility of a fonts. Table 1 shows the recent research done on fonts legibility and recommended fonts for optimum legibility. 
Table 1. Recommended fonts based on previous research results

\begin{tabular}{|c|c|c|}
\hline Research & Fonts Tested & $\begin{array}{l}\text { Most } \\
\text { Recommended } \\
\text { Fonts }\end{array}$ \\
\hline (Hill and Scharff, 1997) & $\begin{array}{l}\text { Arial, Courier New, and } \\
\text { Times New Roman }\end{array}$ & $\begin{array}{l}\text { Times New } \\
\text { Roman }\end{array}$ \\
\hline $\begin{array}{l}\text { (Yager, Aquilante, and } \\
\text { Plass, 1998) }\end{array}$ & Swiss, and Dutch & Swiss \\
\hline $\begin{array}{l}\text { (Boyarski, Neuwirth, } \\
\text { Forlizzi, and Regli, 1998) }\end{array}$ & $\begin{array}{l}\text { Georgia, Times Roman, and } \\
\text { Verdana }\end{array}$ & $\begin{array}{l}\text { Georgia, and } \\
\text { Verdana }\end{array}$ \\
\hline (Bernard and Mills, 2000) & $\begin{array}{l}\text { Arial, and Times New } \\
\text { Roman }\end{array}$ & Arial \\
\hline $\begin{array}{l}\text { (Bernard, Liao, and Mills, } \\
\text { 2001) }\end{array}$ & $\begin{array}{l}\text { Arial, Verdana, Georgia, } \\
\text { Times New Roman. }\end{array}$ & $\begin{array}{l}\text { Aria, and } \\
\text { Verdana }\end{array}$ \\
\hline $\begin{array}{l}\text { (Bernard, Lida, Riley, and } \\
\text { Janzen, 2002) }\end{array}$ & $\begin{array}{l}8 \text { fonts including Verdana, } \\
\text { Arial, Times New Roman } \\
\text { and Courier New }\end{array}$ & Verdana \\
\hline (V. M. Subbaram, 2004) & $\begin{array}{l}\text { Verdana, Arial, Georgia, and } \\
\text { Times New Roman }\end{array}$ & Verdana \\
\hline (Sheedy et al., 2005) & $\begin{array}{l}\text { Arial, Georgia, Times New } \\
\text { Roman, and Verdana }\end{array}$ & Verdana \\
\hline (Mackiewicz, 2006) & $\begin{array}{l}10 \text { fonts including Verdana, } \\
\text { Times New Roman, and } \\
\text { Arial }\end{array}$ & Gil Sans \\
\hline $\begin{array}{l}\text { (B. S. Chaparro, Shaikh, } \\
\text { and Chaparro, 2006) }\end{array}$ & $\begin{array}{l}\text { Cambria, Constantia, Corbel, } \\
\text { Candara, Calibri, Consolas, } \\
\text { Times New Roman, and } \\
\text { Verdana }\end{array}$ & $\begin{array}{l}\text { Consolas, and } \\
\text { Cambria }\end{array}$ \\
\hline (Li and Suen, 2010) & $\begin{array}{l}15 \text { fonts including Times } \\
\text { New Roman, and Arial }\end{array}$ & $\begin{array}{l}\text { Times New } \\
\text { Roman }\end{array}$ \\
\hline $\begin{array}{l}\text { (Ali, Wahid, Samsudin, and } \\
\text { Idris, 2013) }\end{array}$ & $\begin{array}{l}\text { Georgia, Verdana, Times } \\
\text { New Roman, and Arial }\end{array}$ & $\begin{array}{l}\text { Georgia, and } \\
\text { Verdana }\end{array}$ \\
\hline $\begin{array}{l}\text { (Hojjati and Muniandy, } \\
\text { 2014) }\end{array}$ & $\begin{array}{l}\text { Times New Roman, and } \\
\text { Verdana }\end{array}$ & Verdana \\
\hline
\end{tabular}

\section{FONT SIZE}

Font sizes do influence greatly on legibility. Proven by the previous research result, the larger the size of fonts the more legible it is. (V. M. Subbaram, 2004), on p. 200 revealed that larger font was usually more legible than smaller font.However, (C. B. Mills and Weldon, 1987) research indicate that, font that too large might slow down the reading speed since the user has to scan a 
larger area to acquire the same amount of information.Eye tracking studies done by (Beymer et al., 2008) have proved that, sweeping time does increase for large font types, therefore slowing the reading speed. This effect is also found in (Beymer, Russell, and Orton 2005) research on the effect of line length on reading.On the other hand, Beymer et al. research result however indicates that, although the small font is reducing the sweeping time. It is however increasing the fixation time compared to a larger font size.Based on (Bernard et al., 2002), (Bhatia, Samal, Rajan, and Kiviniemi, 2011), and (Ivory, and Hearst, 2002) researches, they indicated that font size at least $12 \mathrm{pt}$ is the best suited for the web page.Table 2 below summarizes the studies that have been conducted on font size.

Table 2.Recommended font size based on previous research results

\begin{tabular}{|c|c|c|}
\hline Researches & $\begin{array}{l}\text { Font sizes } \\
\text { tested }\end{array}$ & Recommended font size \\
\hline (Bernard and Mills, 2000) & $10 \mathrm{pt}$, and $12 \mathrm{pt}$ & $12 \mathrm{pt}$ \\
\hline (Bernard et al., 2002) & $\begin{array}{l}10 \mathrm{pt}, 12 \mathrm{pt}, \text { and } \\
14 \mathrm{pt}\end{array}$ & $12 \mathrm{pt}$ \\
\hline $\begin{array}{l}\text { (Beymer, Russell, and Orton, } \\
\text { 2008) }\end{array}$ & $\begin{array}{l}10 \mathrm{pt}, 12 \mathrm{pt} \text {, and } \\
14 \mathrm{pt}\end{array}$ & $14 \mathrm{pt}$ \\
\hline $\begin{array}{l}\text { (McCarthy and } \\
\text { Mothersbaugh, 2002) }\end{array}$ & $8 \mathrm{pt}$, and 10pt & No significant difference \\
\hline (Bernard, 2003) & $\begin{array}{l}10 \mathrm{pt}, 12 \mathrm{pt}, \text { and } \\
14 \mathrm{pt}\end{array}$ & No significant difference \\
\hline (V. M. Subbaram, 2004) & $\begin{array}{l}8 \mathrm{pt}, 10 \mathrm{pt}, 12 \mathrm{pt} \\
\text { and } 14 \mathrm{pt}\end{array}$ & $\begin{array}{l}\text { At least } 10 \mathrm{pt}, 14 \mathrm{pt} \text { is the } \\
\text { most legible }\end{array}$ \\
\hline $\begin{array}{l}\text { (Kim, Min, Subramaniyam, } \\
\text { and Cho, 2014) }\end{array}$ & $\begin{array}{l}8 \mathrm{pt}, 10 \mathrm{pt}, \text { and } \\
12 \mathrm{pt}\end{array}$ & $\begin{array}{l}\text { No significant difference } \\
10 \mathrm{pt} \text {, and } 12 \mathrm{pt} \text {. }\end{array}$ \\
\hline
\end{tabular}

\section{VIDEO DISPLAY TERMINAL RESOLUTION AND FONTS ON WEB TEXT LEGIBILITY}

On the previous section, researches done previously on legibility of web text on fonts selections and properties have been presented.However, improvement on legibility based on the effects of VDT resolution has yet to be discovered. This research will try to discover; 1) If there is an improvement in readability if higher resolution VDT use and 2) Does there any changes required to the existing guidelines, necessary to ensure the legibility of web text?.Based on the previous researches, legibility does influence by the type of fonts and font size used.However, visual improvement achieved by the higher VDT resolutions might improve the legibility and therefore influence the web designers in choosing fonts and or the font sizes used in their web design.This can be very significant, because the quality of a website or web applications might be decreased if usage of the current guideline might be not suitable for higher resolutions. 


\section{EXPERIMENT DESIGN}

This section will discuss the materials and method used in this research experiment. The experiment for this research consists of 2 tests; 1) Legibility test and 2) Subjective preference test. In the legibility test, the selected subjects performed a task-based test. The test requires the selected subjects to read a text displayed using the selected fonts and fonts sizes and count how many words that have spelling error. On the subjective preference test, mental workload is assessed to explore the comfortable level for each fonts and font sizes. In the following sections, the detail information on the subjects, display instruments and the resolution used, and typefaces and font sizes used is presented.

\section{SUBJECTS}

All subjects were recruited randomly from the student population at Politeknik Sultan Haji Ahmad Shah (POLISAS). Below are the criteria of the subjects used in this research experiment;

- Age group: 18-32 years

- Have normal vision or corrected to normal vision.

- Know and used to browse the Internet.

All subjects are assured to have no class or activity for the next two hours to ensure they were not rushing or pressure to complete the experiments due to the tight timeline.

\section{DISPLAY INSTRUMENTS AND RESOLUTION USED}

To ensure the accuracy of the experiments, a set of single model displays or VDT were used. Below is the specification of the VDT used;

- VDT type: Liquid Crystal Display (LCD)

- VDT model: ThinkVision L2440p

- VDT viewable image size: 24-inch

To see the effects of VDT resolution, two resolutions sizes were chosen in this experiment. Table 4 showing the two resolutions used and its pixels per inch (PPI).

Table 4.VDT resolution settings

\begin{tabular}{lllllll}
\hline \multicolumn{2}{l}{ Resolution } & & $\begin{array}{l}\text { Monitor Size } \\
\left(d_{i}\right)\end{array}$ & $\begin{array}{l}\text { Pixel per } \\
\text { inch } \\
(\mathrm{PPI})\end{array}$ & $\begin{array}{l}\text { Pixel } \\
\text { square } \\
\left(\mathrm{PPI}^{2}\right)\end{array}$ & $\begin{array}{r}\text { per } \\
\text { inch }\end{array}$ \\
\hline High & 1920 & 1080 & 24-inch & 91.79 & 8425 \\
\hline Low & 1280 & 1024 & 24-inch & 68.30 & 4664.89 \\
\hline
\end{tabular}

\section{TYPEFACE AND FONT SIZES}

Based on previous researches. Many researchers are not just comparing legibility performance between each font but also the category or type of fonts such as, serif versus sans serif, and based 
on its intended design, fonts designed for printed materials versus fonts design for on-screen viewing. In this research, 6 fonts have been chosen. Table 5 shows the chosen fonts.

Table 5.Fonts used in the experiments

\begin{tabular}{ll}
\hline Serif & Sans-Serif \\
\hline+ Courier & +Arial \\
\hline *Georgia & $*$ Calibri \\
\hline +Times New Roman & $*$ Verdana \\
\hline +Fonts design for printed materials & *Fonts design for on-screen viewing \\
\hline
\end{tabular}

Based on Table 5, each category or type of fonts has 3 types of fonts. The serif has Courier, Georgia and Times New Roman while sans serif have Arial, Calibri and Verdana. To investigate the effects of fonts designed for on-screen viewing versus fonts designed for printed materials, the fonts designed for on-screen viewing have Calibri, Verdana and Georgia while fonts designed for printed materials have Courier, Arial and Times New Roman.

Based on previous research, most of the researchers suggest the use of fonts sizes at least 10 pt. Since the high VDT resolution used, the higher resolution could be able to display the fonts sharper on much smaller fonts. Due to this assumption, in this research, will be using font size from 3 pt to $14 \mathrm{pt}$.

The objective of the experiment is to study the legibility level of web text using the all fonts and font sizes selected in the scope of this research and its effect when viewing on high and low resolution.To achieve the objectives, all fonts and font sizes selected in the scope of this research will be used for displaying text on the VDT.The text used in the experiment is designed using Wilkins Rate of Reading Test text and seeded with random number of words contains error.Wilkins Rate of Reading Test text was chosen because, the text is designed to be visually stressful but at the same time minimizing the linguistic challenge ((Wilkins, Jeanes, Pumfrey, \& Laskier, 1996)). Based on the previous research, the quality of web page is highly depending on the level of easily scan able web text (Morkes and Nielsen (1997)) and based on the definition of legibility presented on previous section, the text used then seeded random number of words that contains spelling error. Fig. 4 illustrates the example of text used in this research.

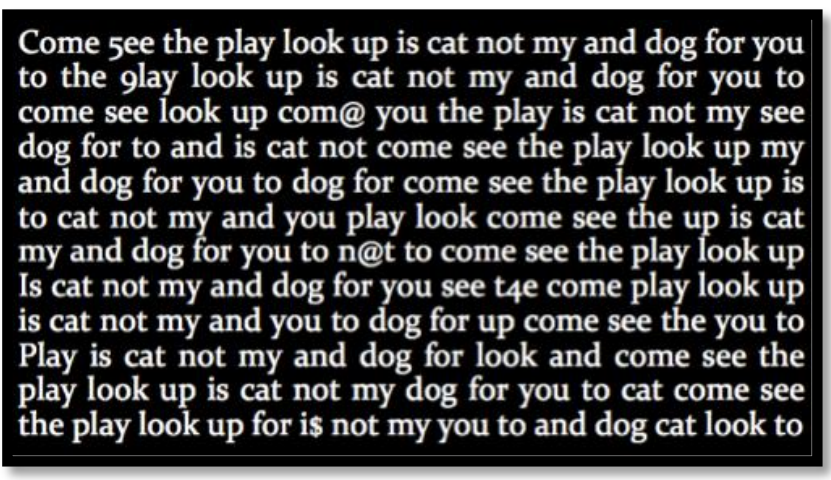

Figure 4.Wilkins Rate of Reading Test text seeded with random words that has spelling error

In Fig. 4, the Wilkins Rate of Reading Test text is seeded with random number of words with the spelling error.The subjects are required to read the whole text and trying to find and count how 
many words that have spelling error. The number of words that have spelling errors that found by the subjects is compared with the actual value and the percentage is calculated. The more near the value of the actual value means the more legible the text is.

\section{EXPERIMENT PROCEDURE}

Two sets of experiments will be done using high and low resolution as the experiment setups. Each experiment will consist about 100 subjects. Before each experiment, subjects were given a brief introduction about the experiments. The subjects then told to sit as comfortable as they please while reading the experiments instructions. They were also asked, tried not to change their sitting position when they start the experiment.

Each font and font sizes will be tested using test text designed for this research. The subjects read the text and evaluated the legibility for each fonts and font sizes by answering two questions. The first one will be collecting the number of words with the spelling error that they found - legibility test. Second question is about how comfortable it is when they perform the legibility test - subjective preference test. On legibility test, there are 5 sets of text and randomly use in the whole experiment.

On this experiment, 6 typefaces will be tested. Each subject is firstly presented a list of characters string design by using the font that is about to be tested with different font sizes (Fig. 5). The subjects are then asked to read the whole string and chose the smallest font size that they think legible enough to read.

Based on the selected font size. The legibility test and subjective preference test will begin and the text is presented using the selected font size and the font that are going to be tested. On this experiment, the colour combination will be set to white colour background with black colour text.

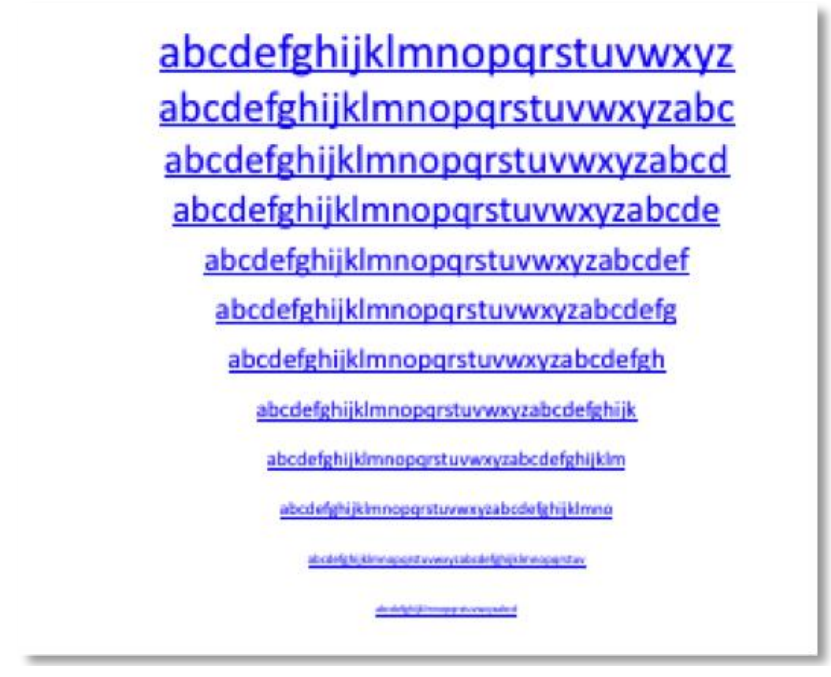

Figure 5. Series of text presented with different font sizes

This experiment method will be repeated using the high and low resolution VDT setting. On this experiment, three hypotheses have been defined as follows;

- $\mathrm{H}_{0} 1$ : All types of fonts have equal legibility performance.

- $\mathrm{H}_{0} 2$ : Sans serif and serif fonts have equal legibility performance. 
- $\mathrm{H}_{0} 3$ : Fonts designed for printed materials and fonts design for on-screen viewing have equal legibility performance

\section{RESULTS}

On the previous section, the design of this research experiment has been presented. In this section, detail analysis for each experiment will be presented in detail based on each VDT resolution.

\section{LEGIBILITY ANALYSIS OF DIFFERENT TYPE FACES ON LOW RESOLUTIONS}

The resolution used in this experiment is 1280x1024 and using 24" VDT. As describe in experiment design section, the density of $\mathrm{PPI}^{2}$ is 4665 . Based on $\mathrm{H}_{0} 1$, all fonts should show equal legibility performance.

Table 6 shows the mean and standard deviation from legibility test experiment. Based on the ANOVA results, Calibri $(\mathrm{M}=85.12 \% \pm 17.476)$ is the best font followed by Arial, Verdana, Times New Roman, Georgia and Courier $(\mathrm{M}=66.67 \% \pm 15.681)$.

Table 6. Mean and SD from legibility test experiment on low resolution

\begin{tabular}{lll}
\hline Fonts & Mean $(\%)$ & Std. Deviation \\
\hline Times New Roman & 73.84 & 15.602 \\
\hline Courier & 66.67 & 15.681 \\
\hline Georgia & 70.77 & 21.640 \\
\hline Arial & 83.27 & 14.574 \\
\hline Verdana & 79.29 & 16.682 \\
\hline Calibri & 85.12 & 17.476
\end{tabular}

Further ANOVA analysis reveals a significance level of 0.05 . A test result (p-value) higher than 0.05 will allow the null hypothesis fails to be rejected; otherwise it has to be rejected. Comparison for each font type has revealed that $\mathrm{p}$-value (smaller than 0.001 ) therefore, $\mathrm{H}_{0} 1$ is rejected.

Table 7. Homogeneity test for each type of fonts in legibility test experiment on low resolution

\begin{tabular}{llll}
\hline Fonts & \multicolumn{2}{l}{ Subset for alpha $=0.05$} \\
\cline { 2 - 3 } & 1 & 2 & 3 \\
\hline Courier & 66.67 & \\
\hline Georgia & 70.77 & \\
\hline Times New Roman & 73.84 & 73.84 & \\
\hline Verdana & & 79.29 & 79.29 \\
\hline Arial & & 83.27 \\
\hline Calibri & & 85.12 \\
\hline
\end{tabular}


Homogeneity test reveals that all the fonts used in this experiment divided into three subsets groups. Based on the results, the best legibility performance included Calibri $(\mathrm{M}=85.12 \%)$, Arial $(\mathrm{M}=83.27 \%)$ and Verdana $(\mathrm{M}=79.29 \%)$ while Times New Roman $(\mathrm{M}=73.84 \%)$ and Georgia $(\mathrm{M}=70.60 \%)$ and Courier $(\mathrm{M}=66.67 \%)$ proven to be a not-recommended font type. However, Times New Roman showed no significant difference with Verdana.

To validate the results further, subjects were asked about how they feel when reading the text using each font (subjective preference test experiment). By using the Likert-scale 1 (Very uncomfortable) to 5 (Very comfortable), the results reveal a p-value (0.028) that is again rejected the $\mathrm{H}_{0} 1$ hypothesis.

Table 8.Mean and SD from subjective preference test experiment on low resolution

\begin{tabular}{lll}
\hline Fonts & Mean & Std. Deviation \\
\hline Times New Roman & 2.66 & 0.853 \\
\hline Courier & 2.82 & 0.769 \\
\hline Georgia & 2.85 & 0.681 \\
\hline Arial & 2.85 & 0.800 \\
\hline Verdana & 3.05 & 0.654 \\
\hline Calibri & 2.70 & 0.789
\end{tabular}

In the subjective preference test experiment, Verdana $(M=3.05 \pm 0.654)$ font proven to be the best fonts followed by Arial, Georgia, Courier, and Calibri, while the lowest subjective preference test score is Times New Roman $(\mathrm{M}=2.66 \pm 0.853)$.

Table 9. Homogeneity test for subjective preference test experiment for each type of fonts

\begin{tabular}{lll}
\hline Fonts & \multicolumn{2}{l}{ Subset for alpha $=0.05$} \\
\cline { 2 - 3 } & 1 & 2 \\
\hline Times New Roman & 2.66 & \\
\hline Calibri & 2.70 & 2.70 \\
\hline Courier & 2.82 & 2.82 \\
\hline Georgia & 2.85 & 2.85 \\
\hline Arial & 2.85 & 2.85 \\
\hline Verdana & & 3.05 \\
\hline
\end{tabular}

On the homogeneity test (table 9), the result reveals that all fonts have no significant difference except for Times New Roman $(M=2.66)$, which is the lowest while Verdana $(M=3.05)$ is the highest. However, all mean values, if rounded to nearest integer, are 3 (Normal) on the Likert scale.

By taking into consideration results from both experiments it is concluded that the best and recommended fonts are Calibri, Arial, and Verdana, while Courier, Georgia, and Times New 
Roman are the less recommended font types. Table 10 ranges from the less legible fonts to the most legible fonts and recommended fonts.

Table 10.Less legible fonts to the most legible fonts on low resolution

\begin{tabular}{ll|l}
\hline Fonts & & \\
\hline Courier & Not Recommended & Less legible fonts \\
Georgia & & \\
\hline Times New Roman & & \\
\hline Verdana & & \\
\hline Arial & Most legible fonts
\end{tabular}

A comparison on a group of fonts, grouped by serif and sans serif fonts was done to investigate more on the characteristics of the fonts. A $t$-test analysis was performed on both legibility and subjective preference test experiments.

Table 11.Comparison between serif and sans serif fonts on low resolution

\begin{tabular}{lllll}
\hline Performance Measured & & Serif Fonts & $\begin{array}{l}\text { Sans } \\
\text { Fonts }\end{array}$ & Serif \\
\hline $\begin{array}{l}\text { Legibility } \\
(\%)\end{array}$ & test experiment & Means & 70.35 & 82.48 \\
\cline { 2 - 4 } & SD & 18.091 & 16.407 \\
\hline $\begin{array}{l}\text { Subjective preference test } \\
\text { experiment (likert scale) }\end{array}$ & Means & 2.78 & 2.87 \\
\cline { 2 - 4 } & SD & 0.770 & 0.759 \\
\hline
\end{tabular}

Table 11 shows the result of combining both legibility test experimental and subjective preference test experiment. A $t$-test analysis on legibility test experiment reveals a $\mathrm{p}$-value (smaller than 0.001) smaller than 0.05; thus, $\mathrm{H}_{0} 2$ is rejected. Therefore for the result of legibility test experiment, it is recommended to use sans serif fonts $(\mathrm{M}=82.48 \% \pm 16.407)$ rather than serif fonts $(\mathrm{M}=70.35 \% \pm 18.091)$.

However, on subjective preference test experiment reveals a p-value (0.183) that is higher than 0.05 , makes it $\mathrm{H}_{0} 2$ fails to be rejected. This therefore failed to see any significant difference between the serif $(M=2.78 \pm 0.770)$ and sans serif $(M=2.87 \pm 0.759)$ fonts. By considering both results, it is recommended to use sans serif fonts for optimal legibility.

Besides serif and sans serif fonts classification, fonts are classified based on its usage. There are two mainly types of font usages, for printed materials and for on- screen viewing. 
Table 12. Comparison between fonts designed for printed materials and fonts designed for onscreen viewing on low resolution

\begin{tabular}{lrlll}
\hline Performance Measured & & $\begin{array}{l}\text { Fonts } \\
\text { for } \\
\text { Materials }\end{array}$ & $\begin{array}{c}\text { Designed } \\
\text { Printed }\end{array}$ & $\begin{array}{l}\text { Fonts Designed } \\
\text { for On-Screen } \\
\text { Viewing }\end{array}$ \\
\hline $\begin{array}{l}\text { Legibility } \\
\text { experiment (\%) }\end{array}$ & test & Means & 74.44 & 78.11 \\
\cline { 2 - 5 } & SD & 16.697 & 19.558 \\
\hline $\begin{array}{l}\text { Subjective preference } \\
\text { test experiment (likert- }\end{array}$ & Means & 2.78 & 2.87 \\
\cline { 3 - 5 } scale) & SD & 0.808 & 0.720 \\
\hline
\end{tabular}

Table 12 shows the results of combining both legibility test experimental and subjective preference test experiments for both types of font. On legibility test experiment, the result reveals a p-values (0.031) less than 0.05 therefore $\mathrm{H}_{0} 3$ is rejected. On subjective preference test experiment, the p-value (0.197) is higher than 0.05 and therefore $\mathrm{H}_{0} 3$ fails to be rejected. Statistically, fonts designed for on-screen $(\mathrm{M}=78.11 \pm 19.588)$ have a slight advantage over fonts designed for printed materials $(M=74.44 \pm 16.697)$.

Subjects were presented with a list of fonts with different sizes for each type of fonts tested. The subjects will then choose which font size is the smallest and legible enough to proceed with legibility test experiment of different typefaces.

Table 13: Mean and SD for font size on low resolution

\begin{tabular}{lll}
\hline Performance Measured & Means & SD \\
\hline Fonts Sizes (pt) & 9.54 & 2.370 \\
\hline
\end{tabular}

Table 13 reveals the result for font size analysis. Based on the results, it is revealed that the recommended font size $(\mathrm{M}=9.54 \mathrm{pt} \pm 2.370)$ is minimum $10 \mathrm{pt}$.

\section{LEGIBILITY ANALYSIS OF DIFFERENT TYPEFACES ON HIGH RESOLUTIONS}

The resolution used in this experiments is 1920x1080 using a 24" VDT. As described in experiment design section, the density of pixel per square inch is 8425 , which is almost double the amount of pixel per square inch used for low resolutions. Based on $\mathrm{H}_{0} 1$ all fonts should have equal legibility performance. However, ANOVA results revealed that p-value (less than 0.001), thus rejecting $\mathrm{H}_{0} 1$. 
Table 13.Means and standard deviation from legibility test experiment on high resolution

\begin{tabular}{lll}
\hline Fonts & Mean $(\%)$ & Std. Deviation \\
\hline Times New Roman & 72.41 & 13.305 \\
\hline Courier & 70.95 & 15.603 \\
\hline Georgia & 80.05 & 13.706 \\
\hline Arial & 85.81 & 13.979 \\
\hline Verdana & 87.72 & 13.644 \\
\hline Calibri & 93.86 & 12.119
\end{tabular}

Based in table 13, on legibility test experiment is the best while Courier $(\mathrm{M}=70.95 \% \pm 15.603)$ font is the lowest legibility score. To determine the significant difference for each type of fonts, table 14 reveals the results from homogeneity test.

Table 14.Homogeneity test for each type of fonts on legibility test on high resolution

\begin{tabular}{llcll}
\hline Fonts & \multicolumn{4}{l}{ Subset for alpha $=0.05$} \\
\cline { 2 - 4 } & 1 & 2 & 3 & 4 \\
\hline Courier & 70.95 & & & \\
Times New Roman & 72.41 & & & \\
Georgia & & 80.05 & & \\
Arial & & 85.81 & \\
Verdana & & 87.72 & \\
Calibri & & & 93.86 \\
\hline
\end{tabular}

A further homogeneity test revealed that the fonts are divided into 4 subsets. The results also clearly reveal that Calibri is the best font while Courier and Times New Roman are the less recommended fonts. For subjective preference test experiments, the results reveal a p-value (0.001) thus again rejecting $\mathrm{H}_{0} 1$. 
Table 15. Mean and SD values from subjective preference test experiment for each type of fonts on high resolution

\begin{tabular}{lll}
\hline Fonts & Mean $(\%)$ & Std. Deviation \\
\hline Times New Roman & 2.76 & 0.633 \\
\hline Courier & 2.84 & 0.632 \\
\hline Georgia & 3.03 & 0.535 \\
\hline Arial & 2.97 & 0.602 \\
\hline Verdana & 3.01 & 0.617 \\
\hline Calibri & 3.03 & 0.476 \\
\hline
\end{tabular}

On subjective preference test experiment (Table 15), the results reveal, Calibri $(\mathrm{M}=3.03 \pm 0.476)$ is the best, followed by Georgia, Verdana, Arial, and Courier while Times New Roman ( $M=2.76$ $\pm 0.663)$ is the lowest.

Table 16. Homogeneity test for subjective preference test experiment for each type of fonts on high resolution

\begin{tabular}{lll}
\hline Fonts & \multicolumn{2}{l}{ Subset for alpha $=0.05$} \\
\cline { 2 - 3 } & 1 & 2 \\
\hline Times New Roman & 2.76 & 2.84 \\
\hline Courier & 2.84 & 2.97 \\
\hline Arial & 2.97 & 3.01 \\
\hline Verdana & 3.03 \\
\hline Georgia & 3.03 \\
\hline Calibri & \\
\hline
\end{tabular}

Based in table 16 it is revealed that Calibri, Georgia, and Verdana are the best and recommended fonts while Times New Roman is clearly the most not recommended font. The results also reveal that all mean values when rounded to the nearest integer are 3 (Normal) on the Likert scale.

By combining both results, it is concluded that Times New Roman and Courier is the less recommended fonts while Arial, Verdana, Georgia and Calibri is the most recommended fonts. Table 4.13 shows the less legible fonts to the most legible fonts and recommended fonts. 
Table 17.Less legible fonts to the most legible fonts on high resolution

\begin{tabular}{lll}
\hline Fonts & Not recommended fonts & Less legible fonts \\
\hline Courier & & \\
\hline Times New Roman & \\
\hline Arial & & Mergia \\
\hline Calibri & \\
\hline
\end{tabular}

A comparison on a group of fonts, grouped by serif and sans serif fonts was done to investigate more on the characteristics of the fonts. $t$-test analysis were done on both legibility test and subjective preference test experiments.

Table 18.Comparison between serif and sans serif fonts on high resolution

\begin{tabular}{lllll}
\hline Performance Measured & & Serif Fonts & $\begin{array}{l}\text { Sans } \\
\text { Fonts }\end{array}$ & Serif \\
\hline Legibility test experiment (\%) & Means & 74.49 & 89.14 \\
\cline { 2 - 4 } & SD & 14.765 & 13.671 \\
\hline $\begin{array}{l}\text { Subjective preference } \\
\text { experiment (likert-scale) }\end{array}$ & test & Means & 2.88 & 3.01 \\
\cline { 2 - 4 } & SD & 0.610 & 0.567 \\
\hline
\end{tabular}

In analysis on both type of experiments, reveal p-value (less than 0.001) for legibility test experiment and p-value (0.004) for subjective preference test experiment, less than 0.05 therefore rejecting $\mathrm{H}_{0} 2$. Based on the results (Table 18), sans serif $(\mathrm{M}=89.14 \% \pm 13.671)$ fonts do have statistically significant advantage over serif $(M=74.49 \% \pm 14.765)$ fonts on legibility test experiment. Subjective preference test experiments also reveal that sans serif $(\mathrm{M}=3.01 \pm$ $0.567)$ has statistically significant advantage over serif $(M=2.88 \pm 0.610)$.

Analysis on fonts designed for printed materials and fonts designed for on-screen viewing reveals a p-value of less than 0.001 for both experiments. These indicate that there is statistically significant advantage between both types of fonts therefore rejecting $\mathrm{H}_{0} 3$. This concludes that, it is recommended to use fonts designed for on-screen $(M=87.19 \% \pm 14.310)$ viewing for optimal legibility compared to font designed for printed $(M=76.38 \% \pm 15.792)$ materials. Table 19 shows the comparison between both types of fonts. 
Table 19. Comparison between fonts designed for printed materials and fonts designed for onscreen viewing on high resolution

\begin{tabular}{|c|c|c|c|}
\hline \multicolumn{2}{|l|}{ Performance Measured } & \multirow{2}{*}{$\begin{array}{l}\text { Fonts Designed } \\
\text { for Printed } \\
\text { Materials }\end{array}$} & \multirow{2}{*}{$\begin{array}{l}\text { Fonts Designed } \\
\text { for On-Screen } \\
\text { Viewing }\end{array}$} \\
\hline & & & \\
\hline \multirow{2}{*}{$\begin{array}{l}\text { Legibility test } \\
\text { experiment }(\%)\end{array}$} & Means & 76.38 & 87.19 \\
\hline & SD & 15.792 & 14.310 \\
\hline \multirow{2}{*}{$\begin{array}{l}\text { Subjective preference } \\
\text { test experiment (likert- } \\
\text { scale) }\end{array}$} & Means & 2.86 & 3.02 \\
\hline & SD & 0.627 & 0.544 \\
\hline
\end{tabular}

Subjects were presented with list of fonts with different sizes for each type of font before the legibility test experiments begin. The subjects then choose which font size is the smallest and legible enough to proceed with legibility analysis of different typefaces. The results are presented in Table 20.

Table 20.Mean and SD value for font size on high resolution

\begin{tabular}{lll}
\hline Performance Measured & Mean & SD \\
\hline Fonts Sizes (pt) & 10.10 & 2.689 \\
\hline
\end{tabular}

Table 20 reveals the result for font size analysis. Based on the results it has been revealed that, the recommended font size $(\mathrm{M}=10.10 \mathrm{pt} \pm 2.689)$ is a minimum of $10 \mathrm{pt}$.

Focussing on each analysis, it is revealed that the null hypothesis is being rejected in almost all analysis. Comparing the results between low and high resolution indicates some improvement in terms of legibility. On the next section, deeper analysis will be done to reveal any improvement in legibility between low and high resolution.

\section{DISCUSSION}

On the previous sections, the detail analyses for each resolution settings have been presented. In this section, the comparison between the results and the improvement on legibility due to effects of resolution will be presented and discussed.

\section{HIGH RESOLUTIONS VERSUS LOW RESOLUTIONS}

On the previous sections, detail analysis for each resolution settings has been presented. In this section, the comparison between the results and the improvement on legibility due to the effects of the resolution will be presented and discussed.

However deeper analysis reveals the difference between the two resolutions. On low resolution, the difference between fonts design for printed $(\mathrm{M}=74.44 \%)$ and fonts designed for on-screen viewing $(\mathrm{M}=78.11 \%)$ is only $3.67 \%$. While on high resolution, the difference between fonts design for printed $(\mathrm{M}=76.38 \%)$ and fonts designed for on- screen viewing $(\mathrm{M}=87.19 \%)$ is 
increase to $10.81 \%$. This leads to two findings: 1) The higher screen resolution does increase legibility due to increase in percentage for both type of fonts. 2) The recommended fonts type includes fonts designed for on-screenviewing due to larger difference of mean values and the mean values does increase for both type of fonts compared between the resolutions tested. Figure 6 illustrates the comparison of both types of fonts on high and low resolutions.

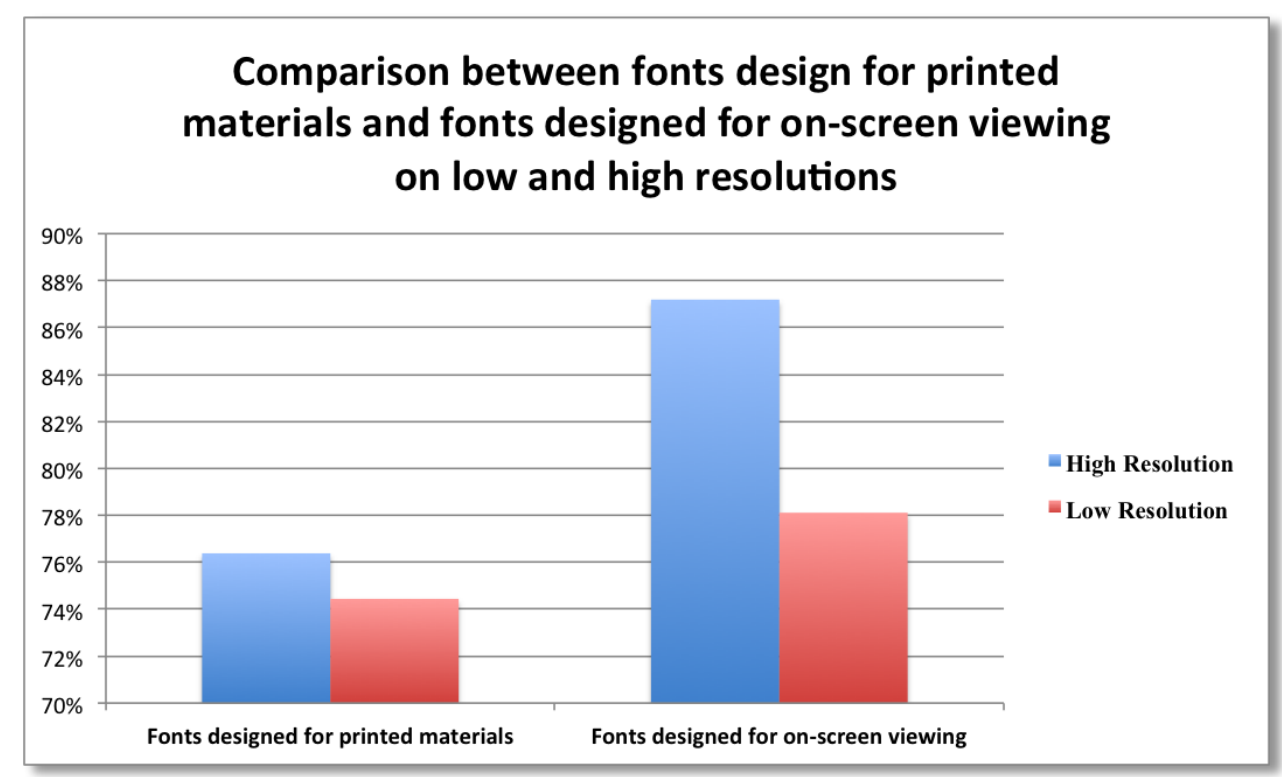

Figure 6.Comparison between both type fonts on high and low resolutions

Serif versus sans serif font results reveal that for low resolution, the difference is $12.49 \%$ for serif $(\mathrm{M}=70.35 \%)$ and sans serif $(\mathrm{M}=82.84 \%)$. On high resolution, the differences increase to $14.65 \%$ for serif $(\mathrm{M}=74.49 \%)$ and sans serif $(89.14 \%)$. This can only concluded that both resolutions recommended sans serif fonts for optimal legibility. Figure 7 shows the difference between serif and sans serif fonts on high and low resolutions.

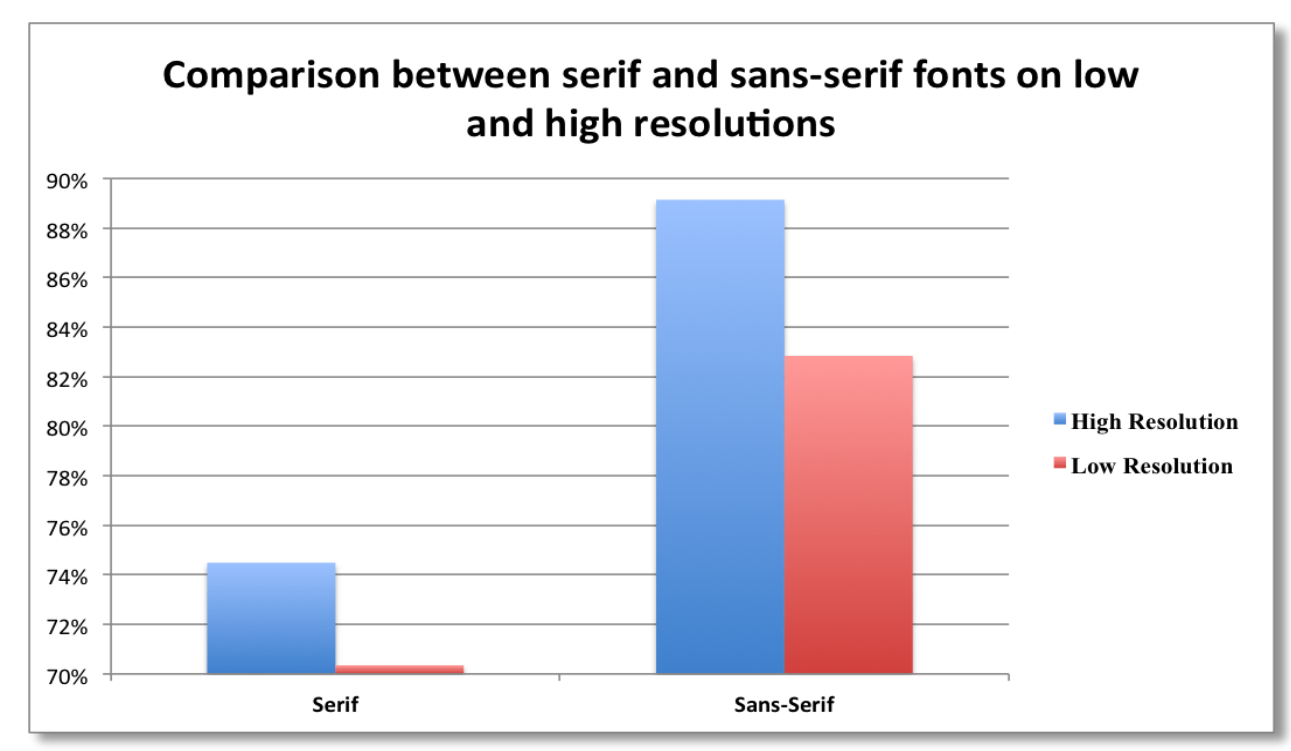

Figure 7. Serif versus sans serif on high and low resolution 
On detailed analysis for each type of fonts reveal that, on high resolutions, which have almost double the amount pixels per-inch, have the advantages over the low resolution in terms of legibility performance. Figure 8 illustrates the difference for all type of fonts on both resolutions. Based on the details of the results, Georgia font has seen an improvement on high resolution. This has led to the recommendation of Georgia for high resolution but not low resolution.

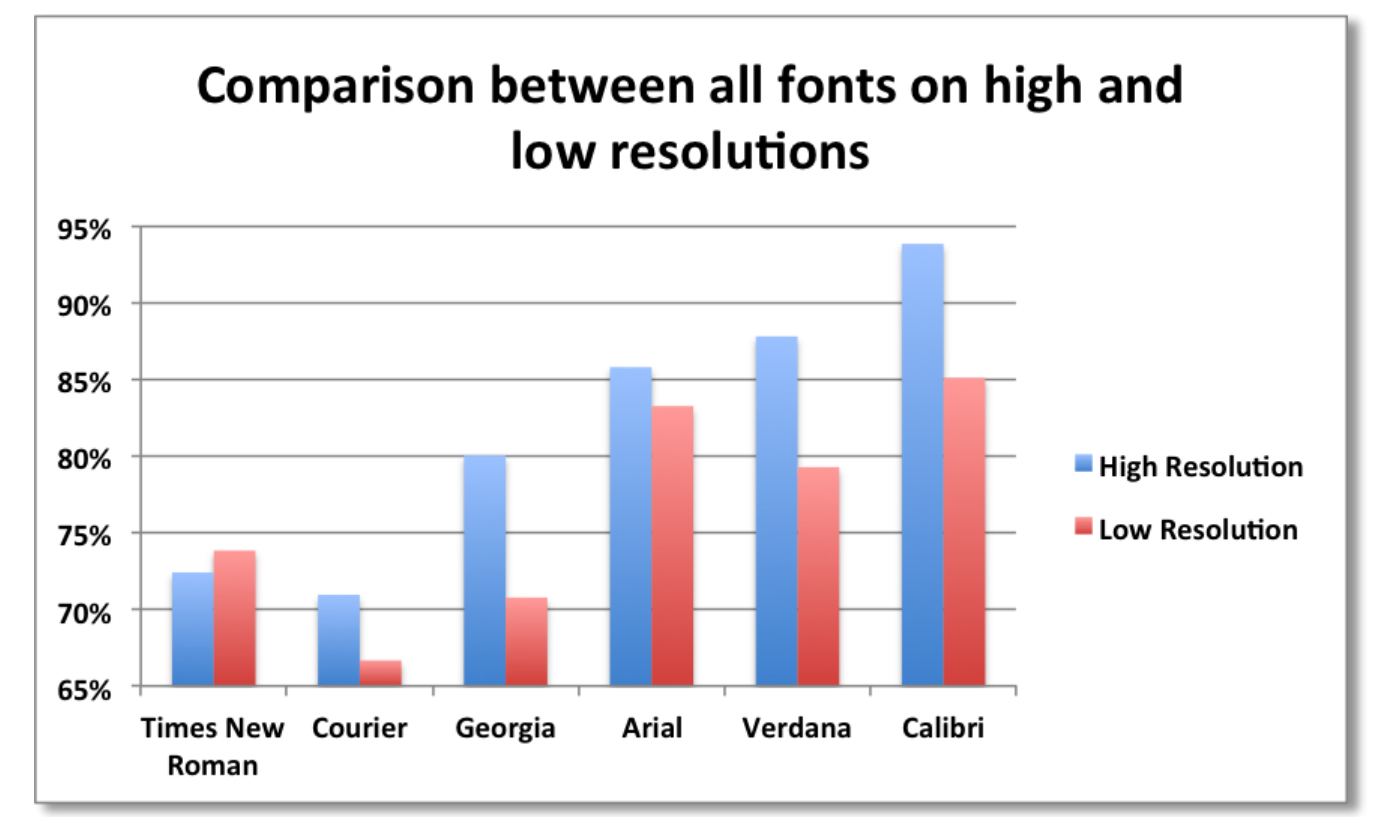

Figure 8. Comparison between all fonts on high and low resolutions

\section{CONCLUSION}

This study has presented a detailed analysis of web text readability and the possible effects on the resolution of VDT in the selection of the type of font and font size.Comparisons between resolutions have successfully indicated improvement on legibility.However, despite the resolution of VDT used, leads to almost twice the number of pixels in density at a resolution higher compared to the low resolution. The results did not show any significant differences to lead to any changes in the guidelines or recommendations available.As a final conclusion, the legibility of web text does be influenced significantly by the design of the fonts and sizes of fonts but not on VDT resolution. Table 21 shows the results for both resolutions derived from the results of this research.In this research, the conducted experiment has successfully explored and proved the possibility of legibility improvement derived by using higher resolution on different configuration set of the fonts and font sizes. However recent researches done, also proved colour combination for text and background also influence legibility level (Huang, 2012, Rello and Marcos, 2012 and Hashim, Abdul Majid, and A Mustafa, 2013).As an extension of this study, a possible change in the results of previous studies may occur when including VDT resolution as one of the variables in the study. 
Table 21.Legibility guideline recommended based on the results from this research

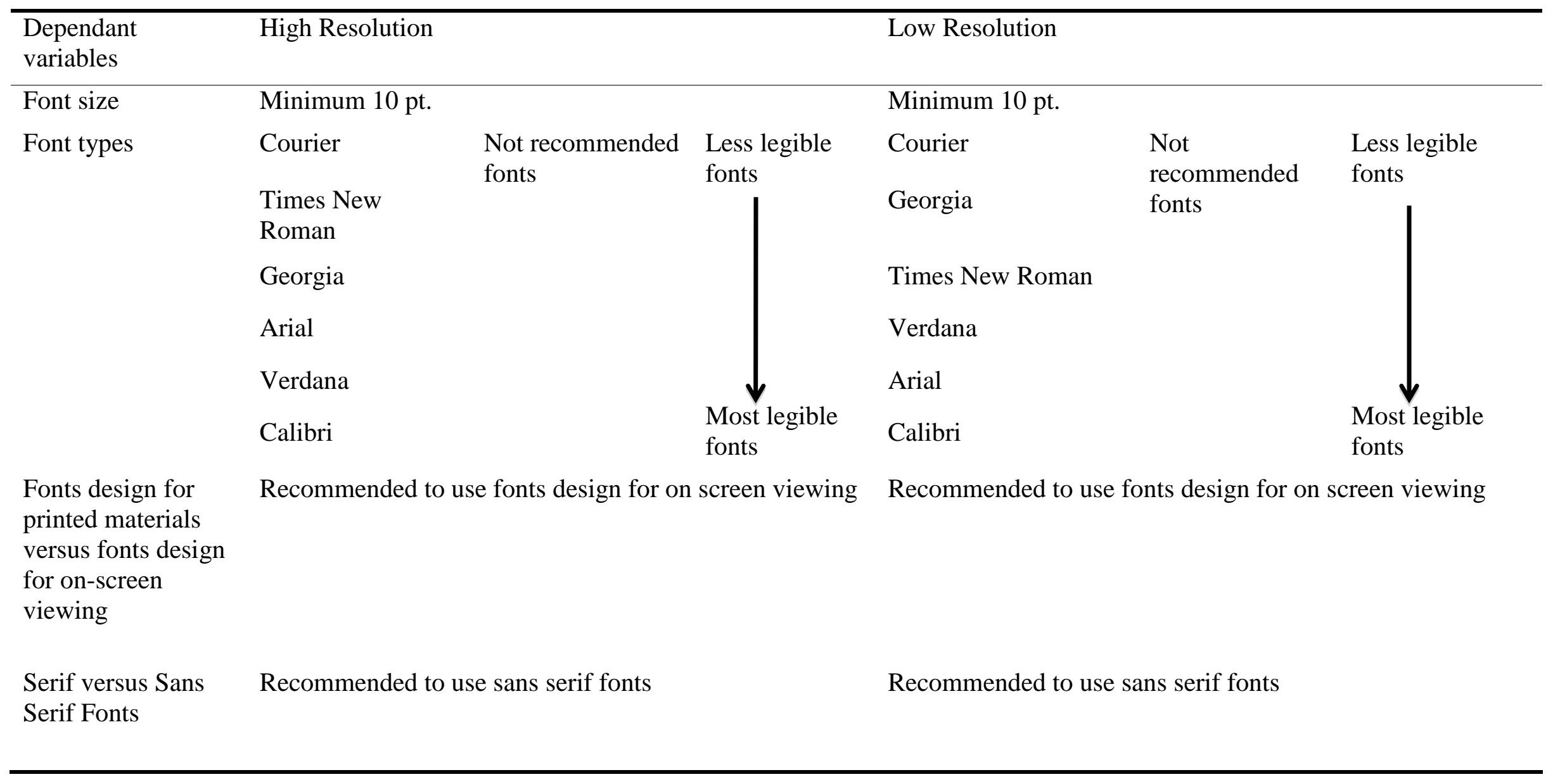




\section{ACKNOWLEDGEMENT}

The author would like to thank the Universiti Malaysia Pahang - Postgraduate Research Scheme (GRS 120361) on financial assistance in this research. Thanks also Polytechnic Sultan Haji Ahmad Shah (POLISAS) especially in Mathematics, Science and Computer Department staff and students for their dedication in lab experiments.

\section{REFERENCES}

Ali, A. Z. M., Wahid, R., Samsudin, K., \& Idris, M. Z. (2013). Reading on the Computer Screen: Does Font Type has Effects on Web Text Readability? International Education Studies, 6(3).

Arditi, A., \& Cho, J. (2005).Serifs and font legibility.Vision research, 45(23), 29262933.

Banerjee, J., Majumdar, D., \& Pal, M. S. (2011). Readability, subjective preference and mental workload studies on young indian adults for selection of optimum font type and size during onscreen reading. Al Ameen Journal of Medical Sciences. http://www.alameenmedical.org/ajms/ArticlePDFs/AJMS.4.2.2011\%20p\%20131143.pdf (Accessed on July 1, 2014)

Bernard, M. (2003). Criteria for optimal web design (designing for usability). Software Usability Research Laboratory.

http://uwf.edu/ddawson/d3net/documents/web_usability/optimal\%20web\%20desig n.pdf (Accessed on June 1, 2014)

Bernard, M., \& Mills, M. (2000, July 8). So, What Size and Type of Font Should I Use on My Website? International Computer \& Instructional Technologies Symposium. http://usabilitynews.org/so-what-size-and-type-of-font-should-i-use-on-my-website/ (Accessed on June 1, 2014)

Bernard, M., Liao, C. H., \& Mills, M. (2001).The effects of font type and size on the legibility and reading time of online text by older adults (p. 175).Presented at the CHI '01 extended abstracts, New York, USA: ACM Press.

Bernard, M., Lida, B., Riley, S., \& Janzen, K. (2002, January 10). A Comparison of Popular Online Fonts: Which Size and Type Is Best? International Computer \& Instructional Technologies Symposium. http://usabilitynews.org/a-comparison-ofpopular-online-fonts-which-size-and-type-is-best/ (Accessed on June 1, 2014)

Beymer, D., Russell, D. M., \& Orton, P. Z. (2005). Wide vs. Narrow Paragraphs: An Eye Tracking Analysis. In M. F. Costabile\& F. Paternò (Eds.), Human-Computer Interaction - INTERACT 2005 (Vol. 3585, pp. 741-752). Berlin, Heidelberg: Springer Berlin Heidelberg.

Beymer, D., Russell, D., \& Orton, P. (2008). An eye tracking study of how font size and type influence online reading (Vol. 2, pp. 15-18). Presented at the British Computer Society Conference on Human-Computer Interaction, British Computer Society.

Bhatia, S. K., Samal, A., Rajan, N., \&Kiviniemi, M. T. (2011).Effect of font size, italics, and colour count on web usability.International Journal of Computational Vision and Robotics, 2(2), 156.

Boyarski, D., Neuwirth, C., Forlizzi, J., \&Regli, S. H. (1998). A study of fonts designed for screen display (pp. 87-94). Presented at the the SIGCHI conference, New York, New York, USA: ACM Press

Camnalbur, M., \&Mutlu, D. (2011, September 24). REVIEW ABOUT FONT TYPOGRAPHY ON INSTRUCTIONAL DESIGN. International Computer \&Instructional Technologies Symposium. 
http://web.firat.edu.tr/icits2011/papers/27872.pdf (Accessed on June 1, 2014)

Chaparro, B. S., Shaikh, A. D., \&Chaparro, A. (2006). The Legibility of Cleartype Fonts (Vol. 50, pp. 1829-1832). Presented at the Proceedings of the Human Factors and Ergonomics Society Annual Meeting.

Duckett, P. (2002). Envisioning Story: The Eye Movements of Beginning Readers. Literacy Teaching and Learning, 7, 77-89.

Erdogan, Y. (2008). Legibility of websites which are designed for instructional purposes.World Applied Sciences Journal. http://www.idosi.org/wasj/wasj3(1)/13.pdf?origin=publication_detail (Accessed on June 20, 2013)

Hashim, A. A., Abdul Majid, M., \& A Mustafa, B. (2013). Legibility of Web Page on Full High Definition Display (pp. 521-524). Presented at the Advanced Computer Science Applications and Technologies (ACSAT), 2013 International Conference on.

Hill, A., \&Scharff, L. V. (1997).Readability of websites with various foreground/background color combinations, font types and word styles. http://www.mmeissner.de/AHNCUR.html (Accessed on March 17, 2014)

Hojjati, N., \&Muniandy, B. (2014, April).The Effects of Font Type and Spacing of Text for Online Readability and Performance.Contemporary Educational Technology. http://www.cedtech.net/articles/52/525.pdf (Accessed on July 1, 2014)

Huang, S.-M. (2012). The rating consistency of aesthetic preferences for iconbackground color combinations. Applied Ergonomics, 43(1), 141-150.

Ivory, M. Y., \& Hearst, M. A. (2002).Improving Web site design.IEEE Internet Computing, 6(2), 56-63.

Kim, J.-Y., Min, S.-N., Subramaniyam, M., \& Cho, Y.-J.(2014). Legibility difference between e-books and paper books by using an eye tracker. Ergonomics, 57(7), $1102-1108$

Li, Y., \&Suen, C. Y. (2010).Typeface personality traits and their design characteristics (pp. 231-238). Presented at the the 8th IAPR International Workshop, New York, New York, USA: ACM Press.

Mackiewicz, J. (2006). Audience Perceptions of Fonts in Projected PowerPoint Text Slides (pp. 68-76). Presented at the 2006 IEEE International Professional Communication Conference, Saratoga Springs, NY: IEEE.

McCarthy, M. S., \&Mothersbaugh, D. L. (2002). Effects of typographic factors in advertising-based persuasion: A general model and initial empirical tests. Psychology and Marketing, 19(7-8), 663-691.

Mills, C. B., \& Weldon, L. J. (1987).Reading text from computer screens.ACM Computing Surveys, 19(4), 329-357.

Moret-Tatay, C., \&Perea, M. (2011). Do serifs provide an advantage in the recognition of written words? Journal of Cognitive Psychology, 23(5), 619-624.

Morkes, J., \& Nielsen, J. (1997, July 1). Concise, SCANNABLE, and Objective: How to Write for the Web. http://www.nngroup.com/articles/concise-scannable-andobjective-how-to-write-for-the-web/ (Accessed on June 1, 2014)

Nielsen, J. (2008, May 6). How Little Do Users Read? nngroup.com. http://www.nngroup.com/articles/how-little-do-users-read/ (Accessed on June 1, 2014)

Nielsen, J., \&Pernice, K. (2010).Eyetracking Web Usability.New Riders. 
Ou, L. C., Sun, P. L., Huang, H. P., \&Ronnier Luo, M. (2014). Visual comfort as a function of lightness difference between text and background: A cross-age study using an LCD and a tablet computer. Color Research \& Application.

Oxford Dictionaries.(n.d.).legibility. oxforddictionaries.com. http://www.oxforddictionaries.com/definition/english/legibility (Accessed on June 1, 2014)

Poulton, E. C. (1965). Letter differentiation and rate of comprehension in reading. Journal of Applied Psychology, 49(5), 358-362.

Rello, L., \& Marcos, M.-C. (2012). An Eye Tracking Study on Text Customization for User Performance and Preference, 64-70.

Sheedy, J. E., Subbaram, M. V., Zimmerman, A. B., \& Hayes, J. R. (2005).Text Legibility and the Letter Superiority Effect. Human Factors: The Journal of the Human Factors and Ergonomics Society, 47(4), 797-815.

Soleimani, H., \&Mohammadi, E. (2012).The Effect of Text Typographical Features on Legibility, Comprehension, and Retrieval of EFL Learners.English Language Teaching, 5(8).

Subbaram, V. M. (2004). Effect of display and text parameters on reading performance. The Ohio State University.

Weisenmiller, E. M. (1999). A study of the readability of on-screen text.Virginia Polytechnic Institute and State University.

Wilkins, A. J., Jeanes, R. J., Pumfrey, P. D., \&Laskier, M. (1996). Rate of Reading TestR: its reliability, and its validity in the assessment of the effects of coloured overlays. Ophthalmic and Physiological Optics, 16(6), 491-497.

Yager, D., Aquilante, K., \&Plass, R. (1998). High and low luminance letters, acuity reserve, and font effects on reading speed. Vision research, 38(17), 2527-2531. 